\title{
Analytical Modelling and Simulation of Photovoltaic Panels and Arrays
}

\author{
H. Bourdoucen* and A. Gastli \\ Electrical and Computer Engineering Department, College of Engineering, Sultan Qaboos University, P.O. Box 33, P.C. 123, \\ Al-Khod, Muscat, Oman
}

Received 22 April 2006; accepted 11 September, 2006

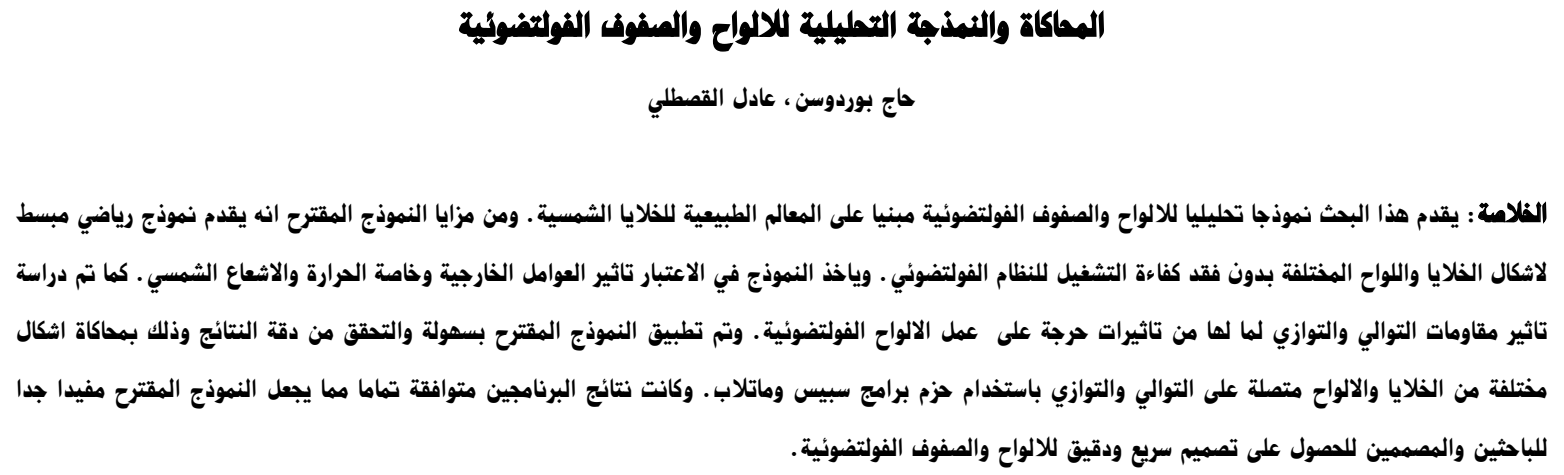

الالنغردات المنتاهية: الذلايا الشمسية، النظم الفولتضوئية، الالواح الفولتضوئية، النذذة التحليلية.

\begin{abstract}
In this paper, an analytical model for PV panels and arrays based on extracted physical parameters of solar cells is developed. The proposed model has the advantage of simplifying mathematical modelling for different configurations of cells and panels without losing efficiency of PV system operation. The effects of external parameters, mainly temperature and solar irradiance have been considered in the modelling. Due to their critical effects on the operation of the panel, effects of series and shunt resistances were also studied. The developed analytical model has been easily implemented, simulated and validated using both Spice and Matlab packages for different series and parallel configurations of cells and panels. The results obtained with these two programs are in total agreement, which make the proposed model very useful for researchers and designers for quick and accurate sizing of PV panels and arrays.
\end{abstract}

Keywords: Photovoltaic cell, Solar cell, PV system, PV panel, Analytical modelling

\section{Introduction}

Photovoltaic (PV) systems have been used worldwide for the last three decades. Their early applications were mainly concentrated in remote areas and in uses were other types of energy are either very expensive or not feasible. However, with the reduction in their fabrication costs, PV systems have seen a tremendous increase in different applications. The maximum efficiency of utilization of solar panels is obtained at maximum power operating point, which is a function of panel physical characteristics and fabrication parameters, solar irradiation, and operating temperature. To design a PV-based system, a model of the panel to be used in simulation prior to implementation is often required. Some PV panel equivalent circuit approximations based on a single-diode model

*Corresponding author’s e-mail: hadj@squ.edu.om have been studied (Ouennoughi, Z and Cheggar, M., 1999; Lee, J.I., Brini, J. and Dimitriadis, C.A., 1998; Araujo, G.L., Sanchez, E. and Marti, M., 1982; Gottschalg, R. et al. 1999; Kaminski, A. et al. 1997). Whereas, the simple models presented give acceptable results only for single crystalline cells. However, for polycrystalline cells, which are cost effective, the models presented are not accurate enough and hence the extended model of two-diode gives better results (Araujo, G.L., Sanchez, E. and Marti, M., 1982). In addition to this, a precise determination of the internal physical parameters of cells and panels is not always possible and the different errors introduced on these parameters during parameter extraction process induce large errors in the models of solar panels.

In this paper, analytical model for equivalent circuit parameters of solar panels and arrays are derived from basic cell models used to build them. The effects of equivalent series and shunt resistances on the panel and array 
The Journal of Engineering Research Vol.4, No.1 (2007) 75-81

characteristics are studied as their effects are important for the operation of PV systems. Spice and Matlab are used for model validation and sensitivity evaluation of the series and shunt resistances. The approach presented is valid for single-diode model as well as for two-diode model provided the specific parameters for a given model are considered, as it will be shown in subsequent section of the paper.

\section{Some Models for Solar Cells and Panels}

\subsection{Analytical Model for Panel and Array}

Solar panels and arrays may be described in terms of a set of electric and optical parameters that represent solar cell properties. This is in addition to the number of cells and panels connected in series and/or in parallel. Most of solar cell models available in the literature represent the solar cell by a single diode in parallel with a current source as shown in 1-a (Ouennoughi, Z. and Cheggar, M., 1999; Lee, J.I., Brini, J. and Dimitriadis, C.A., 1998). However, in order to have a more generalized and accurate model, a two-diode equivalent circuit model shown in 1-b has been developed (Araujo, G.L., Sanchez, E. and Marti, M., 1982; Gottschalg, R. et al. 1999; Kaminski, A. et al. 1997). This model consists of an ideal current source, which represents the optical irradiation connected in parallel with two different diodes $\mathrm{D}_{1}$ and $\mathrm{D}_{2}$ and a shunt resistance $R_{S H}$. All these elements are connected to a series resistance $R_{S}$. Note that diode $D_{1}$ models the generated photocurrent in the space charge region, which dominates the total current at low diode voltages whereas diode $D_{2}$ models the recombination photocurrent outside the space charge region. This photocurrent is more dominant at high diode voltages.

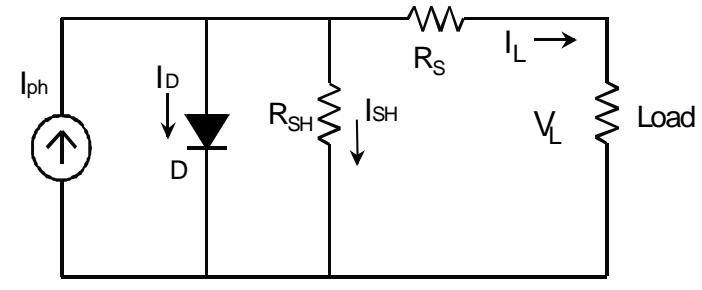

a) Single-diode model

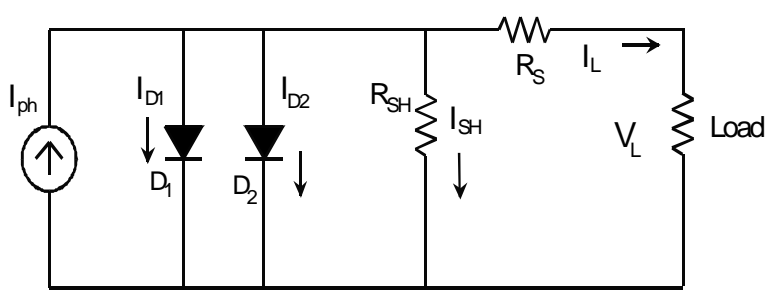

b) Tw-diode model

Figure 1. Solar cell models

The shunt and series resistances are two important parameters in the operation of solar cells. This is because the shunt resistance affects mainly the panel power output and the series resistance affects the efficiency as well as the fill factor (Lee, J.I. et al.; McMahon, T.J. et al.). Therefore, the accuracy in determining these two parameters and the knowledge of the different errors involved in their determination is a key point for a better simulation of the panel and array characteristics. Note also that the absolute values of $R_{S H}$ are very important in cells qualification testing, module performance testing and failure analysis (McMahon, et al.).

With reference to Fig. 1-b, for a generalized panel equivalent circuit, the I-V characteristics of solar cells can be expressed in terms of physical and electrical parameters as,

$\mathrm{I}_{\mathrm{L}}=\mathrm{I}_{\mathrm{ph}}-\mathrm{I}_{\mathrm{D} 1}-\mathrm{I}_{\mathrm{D} 2}-\mathrm{I}_{\mathrm{SH}}$

where, $I_{p h}$ is the total photogenerated current, $I_{L}$ the load current, $I_{D 1}$ and $I_{D 2}$ the equivalent diode currents and $I_{S H}$ the net current through the shunt resistances $R_{S H}$. For a single solar cell or a single panel that can be also considered as a cell, the currents $I_{D 1}, I_{D 2}$ and $I_{S H}$ may be expressed by the following equations (Gottschalg, R. et al. 1999).

$$
\begin{aligned}
& \mathrm{I}_{\mathrm{D} 1}=\mathrm{I}_{\mathrm{SD} 1}\left[\exp \left(\frac{\mathrm{q}}{\mathrm{n}_{1} \mathrm{kT}}\left(\mathrm{V}_{\mathrm{L}}+\mathrm{I}_{\mathrm{L}} \mathrm{R}_{\mathrm{s}}\right)\right)-1\right] \\
& \mathrm{I}_{\mathrm{D} 2}=\mathrm{I}_{\mathrm{SD} 2}\left[\exp \left(\frac{\mathrm{q}}{\mathrm{n}_{2} \mathrm{kT}}\left(\mathrm{V}_{\mathrm{L}}+\mathrm{I}_{\mathrm{L}} \mathrm{R}_{\mathrm{s}}\right)\right)-1\right] \\
& \mathrm{I}_{\mathrm{SH}}=\frac{\mathrm{V}_{\mathrm{L}}+\mathrm{I}_{\mathrm{L}} \mathrm{R}_{\mathrm{S}}}{\mathrm{R}_{\mathrm{SH}}} \\
& I_{p h}=\left(C_{0}+C_{1} T\right) \times G
\end{aligned}
$$

In the above equations, $R_{S}$ and $R_{S H}$ are the series and shunt resistances respectively, $I_{S D 1}$ and $I_{S D 2}$ are diffusion and saturation currents respectively, $n_{1}$ and $n_{2}$ are the diffusion and recombination diode ideality factors, $k$ is the Boltzman's constant, $q$ is the electronic charge, $T$ is temperature in Kelvin, $C_{0}$ and $C_{1}$ are empirical constants modeling the temperature and the irradiation dependence, and $G$ is the irradiation in $\mathrm{W} / \mathrm{m}^{2}$.

Note that in case of a single-diode model shown in Fig. 1-a $I_{D 2}$ must be removed from Eq. (1).

A typical connection configuration of cells and panels that form a PV array used for power system applications to feed a resistive load is shown in Fig. 2. For this typical array configuration with $m$ horizontal units and $n$ vertical units, the cells or panels connected in series are numbered as $P / C_{i 1}$ to $P / C_{i m}$ for a row $i$, where $i$ varies from 1 to $n$, whereas, the panels or cells connected in parallel placed in a given column $j$ are numbered as $P / C_{1 j}$ to $P / C_{n j}$ where $j$ varies from 1 to $m$. Note that $P / C$ represents a cell or panel unit. 


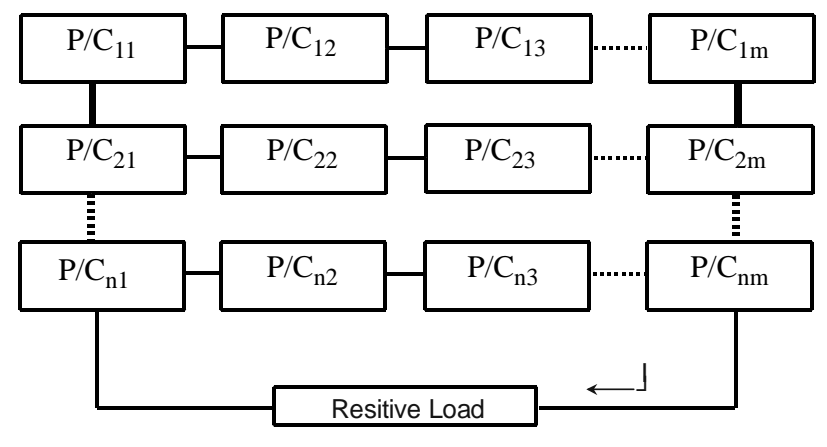

Figure 2. Typical connection of panels and cells forming a PV array that feeds a resistive load.

As indicated above and has been reported in the literature, the extracted values of both the series resistance $R_{S}$ and the shunt resistance $R_{S H}$ have significant errors (Jervase, J., Bourdoucen, H. and Al-Lawati, 2001). It is therefore important to take this in consideration and study the effects of these two parameters on the panel and array characteristics. Based on the models developed elsewhere (Araujo, G.L. et al.; Gottschalg, R. et al.; Kaminski, A. et $a l$.$) and by taking into account typical changes of R_{S}$ and $R_{S H}$ from one cell to another, an improved and useful analytical panel model is proposed. The expressions to be used for the model together with Eq. (1) are given in subsequent section. Typical figures for errors on the $R_{S}$ and $R_{S H}$ have been suggested and their effects are studied by simulation using Matlab/Simulink and Spice software packages. For demonstrating the validity of the analytical model developed, panels having different number of cells and different sizes have been considered. However, typical results will be shown for panel of 72 cells (6x12) with six cells connected in series and twelve in parallel.

Assuming the basic cell parameters similar except for $R_{S}$ and $R_{S H}$, and making appropriate change of variables on saturation currents and ideality factors, then expressions of total currents, ideality factors, equivalent resistances $R_{S}$ and $R_{S H}$ can then be formulated using analytical expressions. This is supported by practical considerations where values of these parameters are affected by the way external connections of cells and panels are done. Based on models shown in Fig. 3 for a set of two ideal cells $D_{1}$ and $D_{2}$ connected in series and in parallel, one can write a set of equations for each type of configuration: These are parallel, series and combination of parallel-series connections.

Parallel connection: with reference to model shown in Fig. 3a, one can write $I_{1}=I_{S 1}\left[\exp \left(v_{P} q /\left(n_{1} k T\right)\right)-1\right]$ for $D_{1}$ and $D_{2}$. Assuming $D_{1}$ and $D_{2}$ having equivalent characteristics, the parallel equivalent circuit composed of the two diodes can be represented by current source $I_{T}=2 I_{1}$ and diode $D$ as shown on the figure. The I-V expression of this circuit can be expressed as:

$$
\mathrm{I}_{\mathrm{T}}=2 \mathrm{I}_{\mathrm{S} 1}\left[\exp \left(\mathrm{v}_{\mathrm{P}} \mathrm{q} /\left(\mathrm{n}_{1} \mathrm{kT}\right)\right)-1\right]
$$

For $m$ cells connected in parallel, saturation current of the equivalent diode is to be multiplied by $m$ and hence the total current becomes:

$$
\mathrm{I}_{\mathrm{T}}=\mathrm{mI}_{1}=\mathrm{mI}_{\mathrm{S} 1}\left[\exp \left(\mathrm{v}_{\mathrm{P}} \mathrm{q} /\left(\mathrm{n}_{1} \mathrm{kT}\right)\right)-1\right]
$$

Similar analysis can be done for finding equivalent series and shunt resistances $R_{S}$ and $R_{S H}$. For the series resistance of a parallel connection of two cells, the current through each resistance is half the total current $I_{T}$, while the voltage drop stays unchanged. Thus, equivalent series resistance $R_{S E}$ of two cells in parallel circuit equals half the single-cell series resistance $R_{S}$. Hence, for $m$ cells connected in parallel $R_{S E}=R_{S} / \mathrm{m}$. The same approach applies for shunt resistances and hence, the equivalent shunt resistance for $m$ cells is $R_{S H E}=R_{S H} / m$.

Series connection: with reference to circuit models of Fig. 3-b, one can write:

$$
\mathrm{I}_{1}=\mathrm{I}_{\mathrm{S} 1}\left[\exp \left(\mathrm{v}_{\mathrm{S}} \mathrm{q} /\left(\mathrm{n}_{1} \mathrm{kT}\right)\right)-1\right]
$$

for $D_{1}$ and $D_{2}$.

The voltage $v_{s}$ for a single cell can be expressed as:

$$
\mathrm{v}_{\mathrm{S}}=\mathrm{n}_{1} \frac{\mathrm{kT}}{\mathrm{q}} \ln \left(\frac{\mathrm{I}_{1}+\mathrm{I}_{\mathrm{S} 1}}{\mathrm{I}_{\mathrm{S} 1}}\right)
$$

Since the two cells connected in series are assumed to have equivalent characteristics, the voltage across the equivalent cell $D$ is $2 v_{s}$. One needs to multiply the ideality factor $n_{1}$ in Eq. (8) and Eq. (9) by 2. For the case of $n$ equivalent cells connected in series, the value of $n_{1}$ is to be multiplied by $n$. Thus, the equivalent voltage and current for a panel of $n$ cells can be expressed as

$$
\begin{aligned}
& \mathrm{v}_{\mathrm{T}}=\mathrm{n} \cdot \mathrm{n}_{1} \frac{\mathrm{kT}}{\mathrm{q}} \ln \left(\frac{\mathrm{I}_{1}+\mathrm{I}_{\mathrm{S} 1}}{\mathrm{I}_{\mathrm{S} 1}}\right) \\
& \mathrm{I}_{\mathrm{T}}=\mathrm{I}_{\mathrm{S} 1}\left[\exp \left(\mathrm{v}_{\mathrm{T}} \mathrm{q} /\left(\mathrm{nn}_{1} \mathrm{kT}\right)\right)-1\right]
\end{aligned}
$$

Similar analysis can also be done for finding equivalent series and shunt resistances $R_{S}$ and $R_{S H}$. The equivalent series resistance of the two cells equals two times the single cell series resistance. Hence, for $n$ cells connected in series the total series resistance $R_{S E}=n R_{S}$. For shunt resistance, the same approach applies, and the equivalent shunt resistance $R_{S H}$ for $n$ cells is $R_{S H E}=n R_{S H}$.

Note that the above approach has also been used to deduce the equivalent panel parameters for a two-cell model.

Combined series-parallel connections: In case of panel or array with a combined series and parallel connections of many solar cells, a change of variables can be done on the physical parameters of a single cell described by Eqs. (1-5) to determine the model of the panel. Hence, expressions of the equivalent parameters can be derived as follows. 


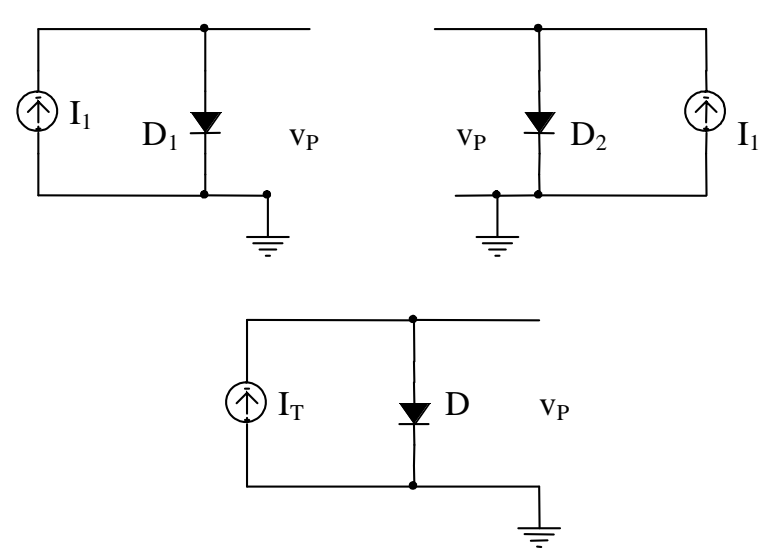

a)

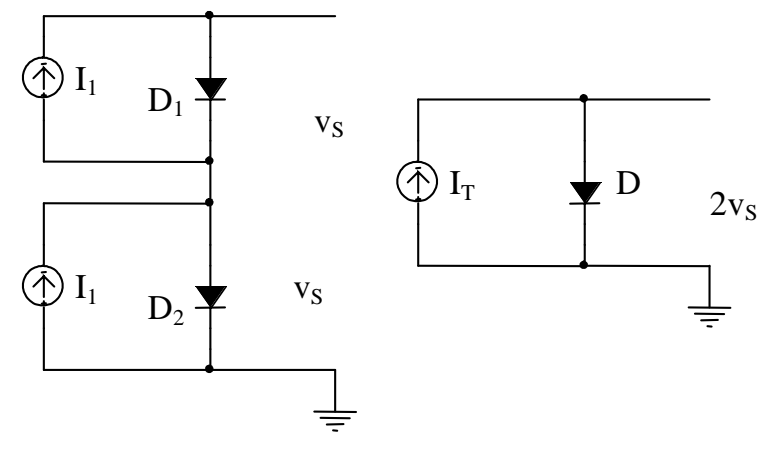

b)

Figure 3. Parallel (a) and series (b) connections of cells, and corresponding equivalent circuits used to build analytical model of panels and arrays

$$
\begin{aligned}
& \mathrm{R}_{\mathrm{SE}}=\sum_{\mathrm{j}=1}^{\mathrm{n}}\left(\sum_{\mathrm{i}=1}^{\mathrm{m}} \mathrm{R}_{\mathrm{S}_{\mathrm{ij}}}^{-1}\right)^{-1}, \mathrm{R}_{\mathrm{SHE}}=\sum_{\mathrm{j}=1}^{\mathrm{n}}\left(\sum_{\mathrm{i}=1}^{\mathrm{m}} \mathrm{R}_{\mathrm{P}_{\mathrm{ij}}}^{-1}\right)^{-1} \\
& \mathrm{n}_{1 \mathrm{E}}=\mathrm{n} . \mathrm{n}_{1}, \mathrm{n}_{2 \mathrm{E}}=\mathrm{n} . \mathrm{n}_{2} \\
& \mathrm{I}_{\mathrm{SD} 1 \mathrm{E}}=\mathrm{m} \cdot \mathrm{ISD}_{\mathrm{SD}}, \mathrm{I}_{\mathrm{SD}} 2 \mathrm{E}=\mathrm{m} \text {.ISD2 }
\end{aligned}
$$

Where, $\mathrm{n}_{1,2 \mathrm{E}}$ and $\mathrm{I}_{\mathrm{SD} 1,2 \mathrm{E}}$ are respectively the ideality factors and saturation currents for the panel equivalent two diode circuit.

Thus, Eqs. (2-4) can be extended to panels and arrays and expressed as follows,

$$
\begin{aligned}
& \mathrm{I}_{\mathrm{D}_{2}}=\mathrm{I}_{\mathrm{SD} 1 \mathrm{E}}\left[\exp \left(\frac{\mathrm{q}}{\mathrm{n}_{1 \mathrm{E}} \mathrm{kT}}\left(\mathrm{V}_{\mathrm{L}}+\mathrm{I}_{\mathrm{L}} \mathrm{R}_{\mathrm{SE}}\right)\right)-1\right] \\
& \mathrm{I}_{\mathrm{D} 2}=\mathrm{I}_{\mathrm{SD} 2 \mathrm{E}}\left[\exp \left(\frac{\mathrm{q}}{\mathrm{n}_{2 \mathrm{E}} \mathrm{kT}}\left(\mathrm{V}_{\mathrm{L}}+\mathrm{I}_{\mathrm{L}} \mathrm{R}_{\mathrm{SE}}\right)\right)-1\right] \\
& \mathrm{I}_{\mathrm{Sh}}=\frac{\mathrm{V}_{\mathrm{L}}+\mathrm{I}_{\mathrm{L}} \mathrm{R}_{\mathrm{SE}}}{\mathrm{R}_{\mathrm{SHE}}}
\end{aligned}
$$

Note that since $R_{S}$ and $R_{S H}$ vary also with optical irradiance and ambient temperature, the equivalent array series and shunt resistances $R_{S E}$ and $R_{S H E}$ will also vary with these two parameters. These are considered in simulations as shown in the following section. A formulation of this dependency for one single cell can be found in (Veissid, N., De-Andrade, A.M., 1991).

To validate the proposed analytical model of panels and arrays to be used for designing PV systems, simulations were done using Matlab and Spice. The following sections describe how the above models were implemented using these two packages.

\subsection{Matlab/Simulink Simulation}

A Matlab/Simulink program was used for to validate the developed solar panel model. Figure 4 shows the solar panel model as it is implemented with Simulink based on previous equations. The inputs to the model are the cell temperature $T$ in ${ }^{\circ} K$ and the solar irradiation $G$ in $\mathrm{W} / \mathrm{m}^{2}$. The output is a voltage that drives a resistive load $R_{L}$. Note that the solar panel current can be varied by changing the load resistance and both voltage and current at the output of the solar panel can be tracked and measured. The model of the panel was based on the implementation of Eqs. (1), (5) and (12-15) with the assumption that all cells' parameters are interrelated according to expressions (12).

\subsection{Spice Simulation}

Circuit models for cells' and panels' configurations shown in Fig. 2 have been implemented by generating models using the model editor in Spice. This has been done for basic solar cells having actual parameters as well as for panels and arrays modeled using the developed analytical approach. The results obtained were compared with the ones obtained using Matlab/Simulink for similar configurations. These are presented in a subsequent section.

It is worth noting that the analytical model presented above is very useful for simulation and modeling of PVbased systems. It simplifies the mathematical computations and design of solar panels without altering physical parameters that are very well known for solar cells. Hence, the parameters derived even though purely mathematical give accurate physical behavior of the PV panel and array.

\section{Results}

Typical parameters of solar cells used to evaluate the developed analytical model are given in (Gottschalg, R. et al. 1999). These are $C_{0}=2.19 \times 10^{-3} \mathrm{~A} \cdot \mathrm{m}^{2} / \mathrm{W}, C_{1}=0$ A. $\mathrm{m}^{2} / \mathrm{W} / \mathrm{K}, G=1000 \mathrm{~W} / \mathrm{m}^{2}, T=55^{\circ} \mathrm{C}, n_{1}=0.99, n_{2}=1.9$, $I_{S D 1}=2.4 \times 10^{-9} \mathrm{~A}, I_{S D 2}=5.5 \times 10^{-5} \mathrm{~A}$. The series and shunt resistances are kept variable to see their effect on the output power of the simulated arrays. However, their values for the basic cell units are $R_{S H}=200 \Omega$ and $R_{S}=2.5 \times 10^{-2}$ $\Omega$. 


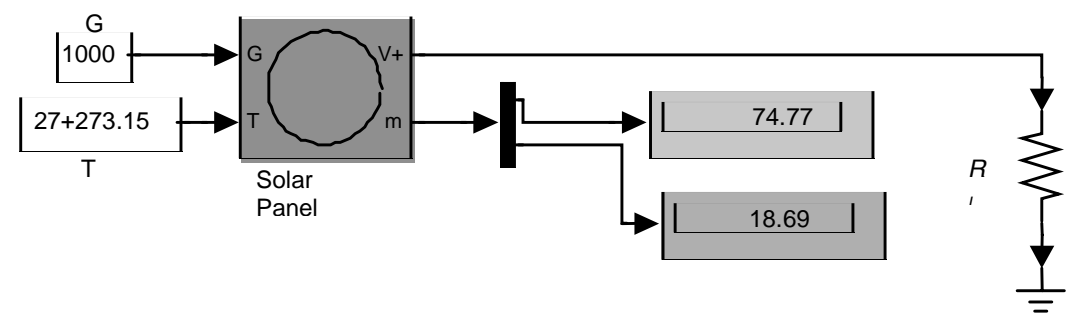

(a) Solar panel simulation block diagram

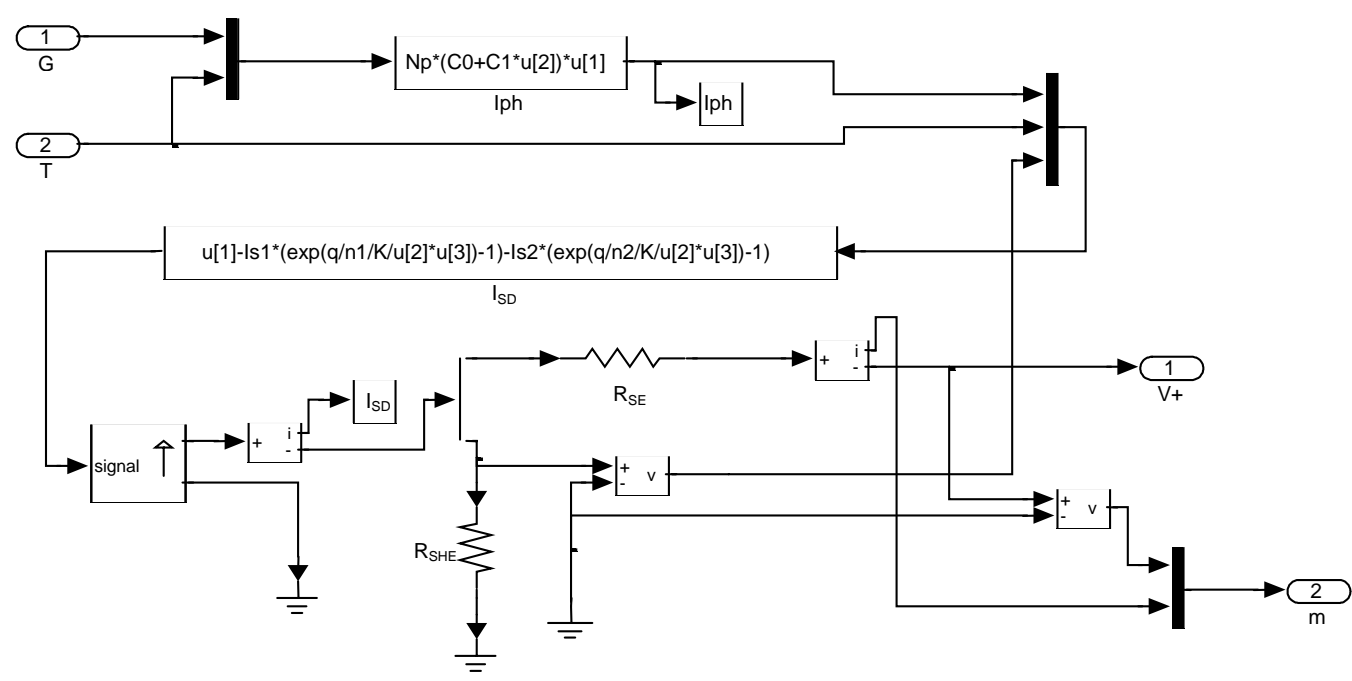

(b) Details of solar panel given in a) above

Figure 4. Solar panel model implemented with Matlab/Simulink

Variations of the output power as a function of the load voltage, for different values of cell and panel equivalent series resistance $R_{S}$ and shunt resistance $R_{S H}$ for the panel of 72 cell configuration are shown in Figs. 5 and 6 respectively. The percentage changes in the values of $R_{S}$ (relative to typical value of $R_{S}=2.5 \times 10^{-2} \Omega$ ) used to obtain these characteristics are $50,100,150$, and $200 \%$. The values of shunt resistance $R_{S H}$ in percentage relative to typical value of $R_{S H}=200 \Omega$ used to obtain these characteristics are also $50,100,150$, and $200 \%$.

Note the significant effect of series resistance fluctuations on the output power (refer to Fig. 5). However, the shunt resistance has practically an insignificant effect. Theses significant fluctuations of the output power versus the output voltage occur at low load resistances as they are more affected by $R_{S}$ rather than $R_{S H}$ which is dominated by the two diodes connect to it in parallel.

On the other hand, the main parameters that affect the output current and voltage of the modeled panel have been considered. These are the solar irradiation $G$ of the site and the temperature $T$ of the panel. To illustrate their effects, the circuit model of Fig. 4 was simulated with different temperatures and solar irradiations using a 72 cell panel. Figure 7 shows the simulation results. Notice that, if the temperature of the panel decreases, the output voltage increases. For instance, when the temperature of the panel is $20^{\circ} \mathrm{C}$ and the irradiation is $1000 \mathrm{~W} / \mathrm{m}^{2}$ the open circuit voltage $\left(\mathrm{V}_{\text {oc }}\right)$ is about $6.3 \mathrm{~V}$. However, if the temperature is decreased to $0^{\circ} \mathrm{C}$ and the irradiation is kept constant, the open circuit voltage $\left(\mathrm{V}_{\mathrm{oc}}\right)$ becomes equal to about 6.6 V. Notice also that reducing the irradiation will result in decreasing the output voltage of the panel. Note also that, if the irradiation is decreased from $1000 \mathrm{~W} / \mathrm{m}^{2}$ to $500 \mathrm{~W} / \mathrm{m}^{2}$, the open circuit voltage is decreased from about $6.3 \mathrm{~V}$ to $5.8 \mathrm{~V}$ at a constant temperature of $20^{\circ} \mathrm{C}$.

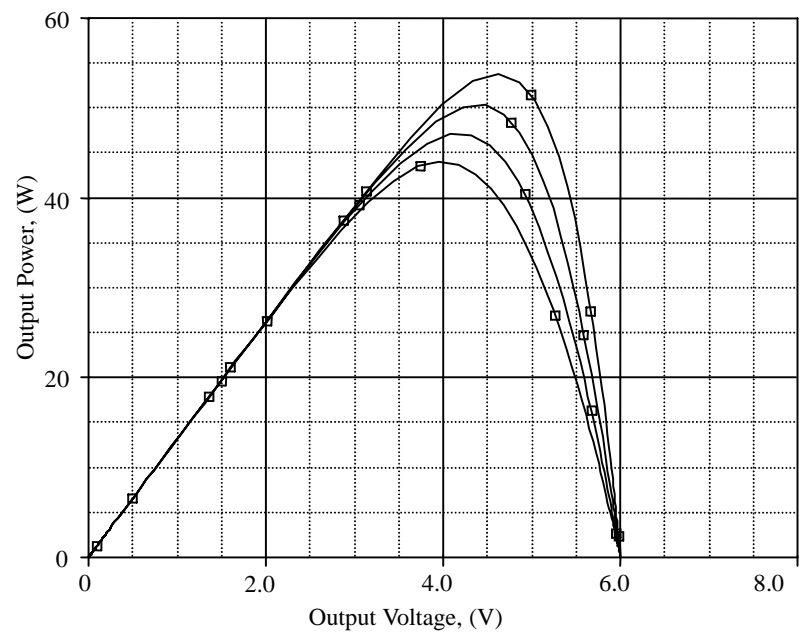

Figure 5. Output power as a function of load voltage for different values of panel equivalent series resistance $\boldsymbol{R}_{S}$ (upper curve corresponding to lower \% change in $R_{s}$ and lowest curve to highest change). The values of $\mathbf{R}_{\mathrm{S}}$ in \% of typical value $2.5 \times 10^{-2} \Omega$ are: 50 , 100,150 and 200 


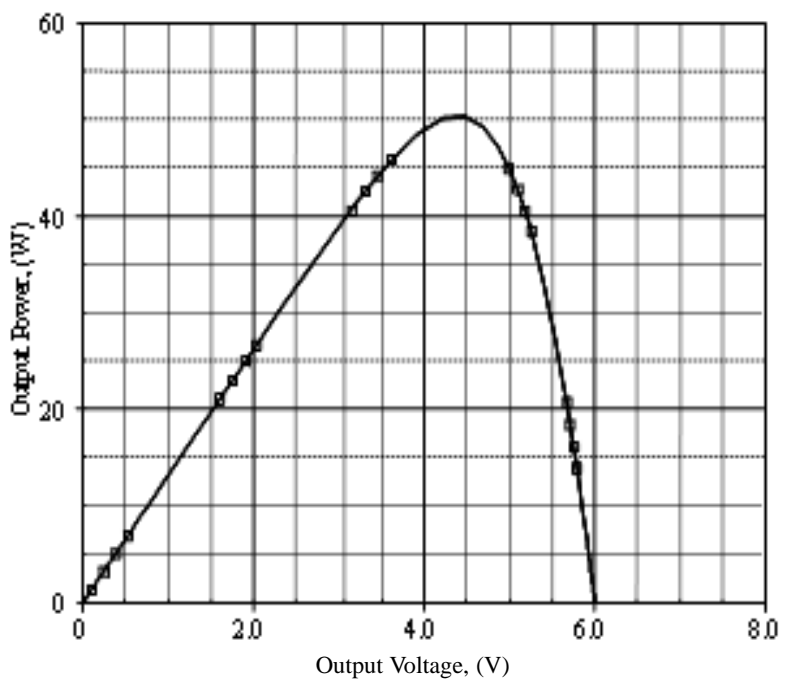

Figure 6. Output power as a function of load voltage for different values of panel equivalent shunt resistsance $\mathbf{R}_{\mathrm{SH}}$. The values of $\mathbf{R}_{\mathrm{SH}}$ in \% of typical value $200 \Omega$ are: 50,100 , 150, and 200

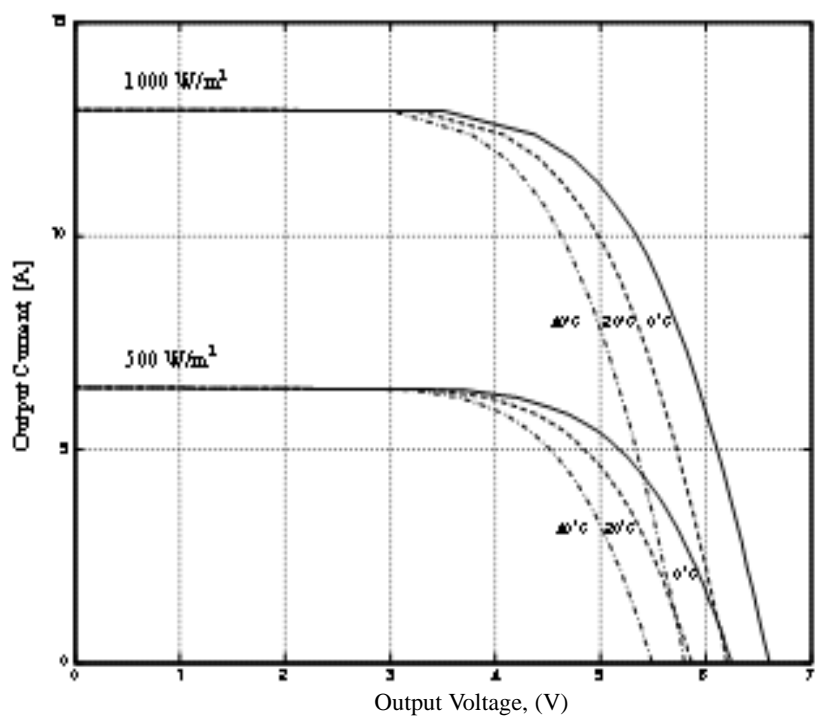

Figure 7. Simulated solar panel I-V characteristics for different temperatures and solar irraditions

The results obtained using Spice and Matlab were in very good agreement. Simulation results shown in Figs. 8a) and 8-b) for $I_{L}-V_{L}$ and $P_{L}-V_{L}$ characteristics confirm this fact.

A sensitivity analysis of the output power with changing $R_{S E}$ and $R_{S H E}$ for a panel of 72 cells has been also carried out. Errors on $R_{S E}$ and $R_{S H E}$ of up to $\pm 40 \%$ of the nominal values of $R_{S E}$ and $R_{S H E}$ which are respectively $0.05 \Omega$ and $400 \Omega$. The results of simulations have shown that deviations of output power due to $40 \%$ change in $R_{S E}$ and $R_{S H E}$ were less that $7 \%$ and $1 \%$, respectively.

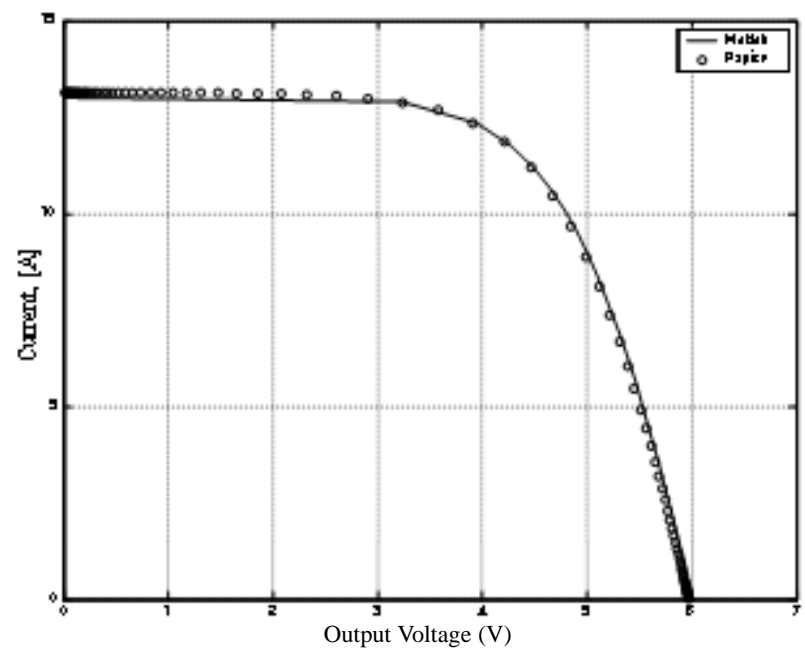

(a) I-V characteristics

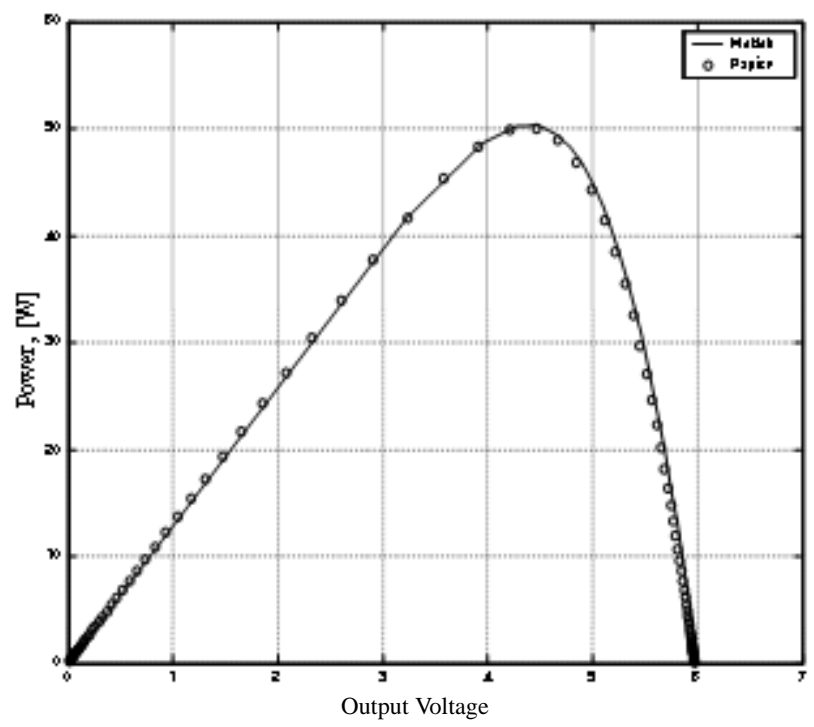

(b) P-V characteristics

Figure 8. Comparison of $I-V$ and $P-V$ characteristics obtained by Matlab for $T=25^{\circ} \mathrm{C}$ and $\mathrm{G}=$ $1000 \mathrm{~W} / \mathrm{m}^{2}$ (72 cells panel)

\section{Conclusions}

An analytical model for PV panels and arrays based on extracted physical parameters of solar cells has been presented in this paper. The proposed approach has the advantage of simplifying mathematical modeling of different cells' and panels' configurations without losing necessary accuracy of system operation. The effects of temperature and solar irradiance have been considered in the modeling. The developed analytical model has been simulated and validated using both Matlab and Spice packages for different cells and panels connected in series and parallel. This makes the proposed model very useful for researchers and systems designers as it allows a quick and accurate sizing of PV panels and arrays. 


\section{References}

Araújo, G. L., Sanchez, E. and M. Marti, 1982, "Determination of the Two-Exponential Solar Cell Equation Parameters from Empirical Data," Solar Cells, 5, pp. 199-204.

Gottschalg, R., Rommel, M., Infield, D.G. and. Kearney, M.J., 1999, "The Influence of the Measurement Environment on the Accuracy of the Extraction of the Physical Parameters of Solar Cells," Journal Meas. Sci. Technol., 10. pp. 797-804.

Jervase, J., Bourdoucen, H. and Al-Lawati, A., 2001, "Solar Cell Parameter Extraction using Genetic Algorithms," Meas. Sci. Technol., 12, pp. 1922-1925.

Kaminski, A., Marchand, J. J., Fave, A. and Laugier, A., 1997, "New Method of Parameters Extraction from Dark I-V Curve," 26th PVSC, pp. 203-205.
Lee, J. I., Brini, J. and Dimitriadis, C. A., 1998, "Simple Parameter Extraction Method for Non-Ideal Schottky Barrier Diodes," Electronics Letters, 34(12), pp. 1268-1269.

McMahon, T. J., Bosso, T. S. and Rummel, S. R., 1996, "Cell Shunt Resistance and Photovoltaic Module Performance," 25th PVSC, pp. 1291-1294.

Ouennoughi, Z. and Cheggar, M., 1999, "A Simpler Method for Extracting Solar Cell Parameters using the Conductance Method," Solid-State Electronics, 43, pp. 1985-1988.

Veissid, N. and De-Andrade, A. M., 1991, "The I-V Silicon Solar Cell Characteristics Parameters Temperature Dependence, An Experimental Study using the Standard Deviation Method," 10th PSEC, Portugal, pp. 43-47. 